February - 2009

\title{
Kothmale Community Radio Interorg Project: True Community Radio or Feel-Good Propaganda?
}

\author{
Liz Harvey-Carter \\ Athabasca University
}

\begin{abstract}
The Kothmale Community Radio and Interorg project in Sri Lanka has been hailed as an example of how a community radio initiative should function in a developing nation. However, there is some question about whether the Kothmale Community Interorg Project is a true community radio initiative that empowers local communities to access ICT services and to participate freely and equally or another feel-good project controlled by successive, repressive Sri-Lankan governments and international partners, as alleged by its critics? After two decades of operation, the evidence shows that the Kothmale project is a cautionary tale about what can go wrong when an ICT project is not strongly promoted as a community-based enterprise. The biggest lesson that the Kothmale model can teach us is that control of community radio must be in the hands of the community exclusively if it is to succeed.
\end{abstract}

Keywords: Kothmale, community radio, Sri Lanka, ICT, Kothmale Interorg Project

\section{Kothmale Community Radio Interorg Project}

The Kothmale Community Radio Project in Sri Lanka, now called the Kothmale Community Interorg Project, has been hailed as an example of how a community radio initiative should function within a developing nation, particularly one that has been embroiled in a long, brutal civil war (FAO, no date; Hughes, 2003; IDS, 2002; Jayaweera, 1998; Op de Coul, 2003; Seneviratne, 2007; Seneviratne, 2000). While this project is described as a success, ostensibly enabling the limited community it serves to participate in ICT and to decide which aspects of their culture(s) will be broadcast or featured on air or online, it can be argued that it has failed to realize its promise as an engine for change and freedom of expression (Gunawardene, 2007). Indeed, one may ask whether the Kothmale Community Interorg Project is a true community radio initiative that empowers local communities to access ICT services and to participate freely and equally or another feel-good project controlled by successive, repressive ${ }^{i}$ Sri-Lankan governments and international partners, as alleged by its critics? In order to answer this question, the project's background is explored: why it was created; by whom; how the project unfolded; how it was, and is, funded; who its listeners and contributors are; and how its content is delivered. 
Then some of the initiatives and applications associated with the project are examined, such as education programmes, community health projects, and cultural transmissions. Finally, the author analyzes the challenges to and criticisms of the Kothmale project, mainly raised by the press, as well as continuing questions about the project's viability.

\section{Background}

Community radio was defined by a meeting of Media South Asia and other community radio groups in 2002 as "a broadcasting organisation established to provide communication support for the social, economic and cultural development of a community within a geographic location and owned and operated by the community on a non-profit basis" (IDS, 2002, p. 2). Although the Kothmale Community Radio Interorg Project or KCRIP (an outgrowth of the earlier Kothmale Community Radio or KCR project) serves its local community in some respects, it does not meet the above definition because it is not owned and operated by its local community.

The radio station and its tower were initially located at the top of a mountain in central Sri Lanka to maximize its broadcast range, and its first program was transmitted in February of 1989. KCR was created in response to a development scheme by the Mahaweli Authority, which displaced over 2,900 families, some 60,000 people, in order to build Sri Lanka's second largest dam project (Pringle, 2001; Venniyoor, 2006). The displaced families needed information about job creation, farming, education, and health in their new communities, and KCR was created to provide this information in an easy-to-access format-radio. It was hoped that KCR would stimulate interest in new technologies among the rural, poverty-stricken people displaced by the dam development and inspire them to learn about and initiate development projects of their own (Dagron, 2001). It was further hoped that the KCR project would help to bridge the digital divide in Sri Lanka (Reddi \& Sinha, 2007). Acting controller of KCR, Sunil Wijesinghe, declared this aspiration in an interview in early 2000: "We have opened the doors to knowledge, understanding and entertainment through radio. This has motivated the community to participate and express themselves freely and receive information without censorship" (Seneviratne, 2000, p. 1).

Both KCR and its progeny KCRIP are the result of the collaborative efforts of many, including UNESCO, the Sri Lankan Ministry of Posts, Telecommunications and the Media, the Sri Lankan Telecommunication Regulatory Commission, and the University of Colombo. The Kothmale project is owned and operated by the Sri Lankan Broadcasting Corporation (SLBC), which provides and regulates trained staff, physical space, and equipment. The SLBC also regulates permission to broadcast; thus, all community radio projects are top-down operations, at least as far as their licensing and core operations. Only the day-to-day operations of each station and their individual communal impact occur at the local level (Pringle \& David, 2002). It is reported by some authorities that the Kothmale project provides broadcast services to approximately 350,000 rural inhabitants in a radius of approximately 25 kilometres from its broadcast tower (Dagron, 2001). Other authors contend that the range of the project is actually 20 kilometres and serves between 200,000 and 230,000 people in 20,50,52, or 60 villages. Still other researchers write that it is impossible to determine the actual number of listeners, participants, and recipients of KCR and KCRIP's benefits (Op de Coul, 2003). 
Initially, UNESCO donated the computer equipment used to run the radio station and trained the staff members, with the understanding that when the initial funding for the project ran out, the project would find ways to become self-funded. By 1998, when it became clear that the original radio project alone did not address the increasing digital divide between the urban and rural population in Sri Lanka, UNESCO again worked with Sri Lankan authorities and partners to create the Interorg project KCRIP, which they hoped would become a pilot model for ICT applications (Pringle, 2001; Pringle \& David, 2002). Project directors sought to address four key issues using the KCRIP model: (1) rural ignorance about new communication technologies and the opportunities they provide, (2) accessibility to same, (3) differing linguistic and cultural expectations, and (4) stimulus for change (Pringle, 2001).

It was hoped that the Kothmale project would provide access to both formal and lifelong learning for community members; create increased opportunities for expansion of local jobs and business creation; reduce the marginalization of the rural poor; and foster an atmosphere of peace and understanding to deter warring factions (Pringle, 2001). Accordingly, the Government of Sri Lanka, through the Telecommunication Regulatory Commission, provided a dedicated 64KB line to provide the communities served by KCR with Internet connectivity and ensured that three access points were built in different villages to increase community access to the project. Thus KCR moved down from its mountain top and into the community, and KCRIP was born as a mini ISP (Pringle, 2001). The lack of infrastructure in this remote central region of Sri Lanka meant that a microwave radio line (Op de Coul, 2003, p. 2) was established between one of the villages and the Kothmale Station and that a Remote Access Server was created to provide dial-up service to other villages and possible future access points, which would be computer training centers (Op de Coul, 2003, p. 2).

At first, Kothmale radio operated on an extremely limited basis as radio station KCR 98.4 FM (Venniyoor, 2006), using a 300 watt transmitter (Reddi and Sinha, 2007), under the rubric of Kothmale Community Radio or KCR (Dagron, 2001; Venniyoor, 2006). By 1991, it was on-air for three hours thrice weekly. In 1998, a cash infusion of \$50,000 from UNESCO enabled the implementation of the Internet part of the radio project and expanded the station's interactive possibilities, turning it from a radio initiative into a true ICT Interorg project dubbed KCRIP. The affordance of direct and independent access to the Internet and the enthusiastic response by community members ensured that by 1999 the station was moved to larger quarters in Mawathura and that it was able to broadcast seven days a week for twelve and a half hours during the week and eight hours on weekends in both Sinhalese and Tamil (Seneviratne, 2007). ${ }^{\text {ii }}$

For the first two years of the KCRIP project, all accessibility costs were paid by the Government of Sri Lanka, but it was understood that those running the station would use this period to generate sufficient income to meet its expenses, approximately USD 1,000 a month. This goal has been accomplished by selling commercial spots on the morning broadcast shows, and it is estimated that this revenue provides approximately $75 \%$ of the station's operating budget. The Sri Lankan Broadcast Corporation retains responsibility for the KCRIP project's financial oversight (Dagron, 2001; Pringle, 2001). 
KCRIP utilizes both direct and indirect means for community members to access the Internet. Community members who can make the often long journey to an access center are free to browse the Internet directly on one of the computers provided. ${ }^{\text {iii }}$ Members sign a log book (kept by the University of Colombo to assess web usage), and cookies record the web sites they surf. ${ }^{\text {iv }}$ They then have a block of time, usually half an hour to an hour to surf free of charge, build a web site, or write and answer e-mail (Jayaweera, 2001; Pringle, 2001). Alternately, community members who either cannot make the journey to an access center, do not have the time to come, or do not want to learn how to browse the Internet, can access the Internet indirectly through the device of radio-browsing (Pringle \& David, 2002, p. 2; Reddi \& Sinha, 2007, p. 263), which means that the disc jockey or programmer of a radio show browses the Internet on behalf of radio listeners, who either call-in and ask questions, mail in postcards, or visit the station to request information. This information is then broadcast as part of a program for the entire community to hear.

Local experts, usually members of the community's elite such as doctors, lawyers, accountants, or educators, either sit in to provide context for and translation of the information gleaned by surfing the Internet, or they act as DJs themselves with regular shows that provide research on specific topics of perceived interest to their fans (Reddi \& Sinha, 2007). This effectively puts control of the information gathered and its interpretation and spin into the hands of local elites, which may be problematic, particularly for members of under-represented minority groups in the communities served. Nevertheless, in concert with the University of Colombo, a multilingual community database of over 600 pages (see http://www.kirana.lk) has been established to house the accumulated information, and CDs are available for loan or sale, which summarize the research on specific topics (Jayaweera, 2001; Pringle, 2001). The KCRIP web site (see www.kothmale.net) also hosts more than 26 sites built by community members and volunteers, which contain information pertinent to both personal and community interests (Pringle, 2001; Reddi \& Sinha, 2007).

On a daily basis, KCR/KCRIP is run by a station manager/controller, which since the inception of the KCR project has been Sunil Wijesinghe, with the assistance of two technicians, two labourers, and one broadcaster (Pringle, 2001). A series of some fifteen relief announcers and a varying number of volunteers complete the staff (Pringle, 2001). KCR FM also operates what is called an active listeners club, which purportedly has great support in the community and operates the $e$ tuktuk project, discussed below (Basu, 2008; Pringle, 2001).

\section{Local Successful Kothmale Social Initiatives}

By actively participating in the Internet project through visits, call-ins, and post cards that contain potential research questions, some of the local community members consciously engage in educational activities (Pringle, 2001). As Pringle notes, some Kothmale listeners and users now have "an expanded local capacity to use ICTs" $(2002$, p. 2). This is touted as being one of the Kothmale project's key achievements. Another is the amount of peer-to-peer training, which is ongoing (Pringle, 2001). After the initial training by staff and a succession of Australian volunteers, ${ }^{v}$ the Kothmale model is demonstrating, at least on a limited basis, that creating local experts is smart business because these local experts are pleased to display their new talents by 
teaching others in their community. So the benefits of teaching a few are expanded exponentially when they in turn teach others, thus broadening the local knowledge base. The project has succeeded so well that the local desire to learn and use the Internet now far outstrips the available Internet accessibility (Pringle, 2001).

The breadth of topics that have been addressed over the years include information about mosquito-repelling plants for local farmers; the development of a web site on scouting; business opportunities, which were researched online and helped to expand local businesses nationally and beyond - these include a palm treacle distributor and a mortuary company, new crafting techniques for local blacksmiths and bamboo artisans, and recipes for local bakers; and English language learning skills and research opportunities for local teachers, to name a few (Pringle \& David, 2002; Jataweera, 2001). The biggest success stories have occurred with local youth who have eagerly embraced the new technology. Many, through volunteering at the station, are now adept enough to create their own web sites and to teach others how to use the Kothmale computers (Pringle \& David, 2002). Another benefit has been the dissemination of human rights information to local communities through association with human rights activists and professionals at Colombo University, whose Human Rights Centre funds the program (Dagron, 2001), and the development of programs that educate women about health and home-related issues of concern to them (Pringle \& David, 2002).

There are two noteworthy features of the Kothmale radio web browsing project: All programmes are presented in time slots that reach the specific listeners who have submitted questions, and all programmes make the web, and how it is actually searched, their focus. The Internet is not merely used as a speedy information-gathering tool, but the reality of how it works is taught to radio listeners, which raises their awareness of Internet technology as an efficient communication and research technology. The DJs explain their actions to listeners as they are performing Internet searches in real-time, thus turning their shows into what Pringle and David call "live webbrowsing telecasts" (2002, p. 6). Regardless of the topic researched in any given programme, all listeners learn something new and expand their frame of reference, which ultimately benefits the entire community.

To disseminate information about the Kothmale project to local villages (and to community members of the poorest culture and language groups, who often do not feel entitled to participate due to their minority status), to increase awareness of ICTs, to encourage women and girls to become more involved, and to train and familiarize the community with Internet technology, the Kothmale project has commissioned a mobile telecentre (Keerthiratne, 2007, p. 1), which drives from village to village, broadcasting the station's programmes and offering community members a taste of the Internet ${ }^{\mathrm{vi}}$ (Basu, 2008; Venniyoor, 2006). To this end, a four-stroke autorickshaw has been converted by local mechanics and outfitted with a mobile radio station, speakers, and Internet capability (Keerthiratne, 2007; Venniyoor, 2006). The e-tuktuk, which can navigate the steepest of mountain passes, is also equipped with an Internet-ready lap-top computer, a power supply unit, a digital camera, a scanner, a CDMA phone, and a battery-operated printer, so that local people can make full use of the mobile studio's capabilities when it visits their community (Basu, 2008; Keerthiratne, 2007; Venniyoor, 2006). They can both upload and download files 
(Venniyoor, 2006), take pictures, scan or print documents, narrowcast audio and video content, broadcast live programming or stream KCR's shows, or use the media center and cordless microphones to put on a concert (Keerthiratne, 2007). The e-tuktuk uses an ancient 50 Watt FM exciter, which is precariously strapped to its roof and transmits via a portable eighteen foot antenna that the crew assembles and disassembles as needed ${ }^{\mathrm{vii}}$ (Venniyoor, 2006).

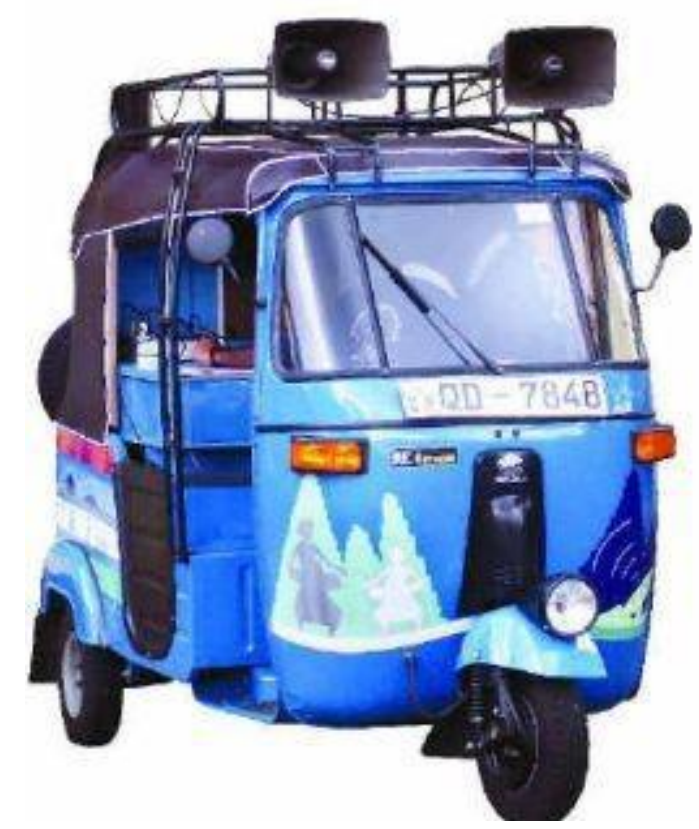

Figure 1. The e-tuktuk, an autorickshaw that serves as a mobile radio station and multimedia centre. Source: Google Images

The e-tuktuk attracts large crowds wherever it goes, and its route is broadcast ahead of time on both KCR FM and the KCRIP web site (Keerthiratne, 2007; Venniyoor, 2006). At a cost of approximately USD 20,000 to build and outfit, its creation is considered such an innovative concept that in December 2007 the e-tuktuk project won the Stockholm Challenge Global Knowledge Partnership Award in Kuala Lumpur in the Public Administration class (Basu, 2008). With daily operating costs of USD 200 a day, ongoing support for the e-tuktuk project is necessary and is currently being borne by the MJM Charitable Foundation for an undisclosed period of time (Basu, 2008). Project members hope that the award will encourage other community radio projects to adopt a similar system (Basu, 2008).

As a final note on the e-tuktuk project, research coordinator for the project, Kosala Keerthiratne, writes that the e-tuktuk is used so often to deliver official Examination Department exam results to schools that the project has had to start charging minimal fees to "cover the Internet bill of the phone and as a contribution for the e-tuktuk" (2007, p. 1). Although the fee is waived for the poorest students, the fact that fees are charged for services may bode well for the upkeep of the e- 
tuktuk, but it may also foreshadow trouble if the fee cannot be waived for the poorest communities in the future.

\section{Challenges and Criticisms}

Nalaka Gunawardene, a noted journalist, science writer, UN consultant, media researcher, and head of TVE Asia Pacific, a non-profit media organization, is an outspoken critic of the Kothmale radio project and asserts that UNESCO "peddles" the Kothmale project as a "feel-good" story (Gunawardene, 2007, p. 1). Gunawardene criticizes the tight bureaucratic control of the Kothmale project by both SLBC and the University of Colombo. Also, he is critical of the fact that no political opinions of any nature may be discussed by either programmers or listeners of the station during programming and that the Internet may not be used for such purposes. ${ }^{\text {viii }} \mathrm{He}$ writes:

A globally persistent myth holds that community radio has been thriving in Sri Lanka for two decades. In reality, these broadcasters [sic] are nothing more than rural transmissions of the fully state-owned and statecontrolled Sri Lanka Broadcasting Corporation (SLBC). Yes, these stations are located in remote areas, involve local people in programme production and broadcast to a predominantly rural audience. But the bureaucracy in Colombo tightly controls content: nothing remotely critical of the government in office is permitted. The rest of the world does not recognize this as community radio. The World Association of Community Broadcasters (AMARC) defines community radio as non-profit with the community having complete control over the content of broadcasts. Ironically, only armed rebels have defied this stranglehold by successive governments. (2006, p. 3)

This assertion is contradicted by Sunil Wijesinghe, a local Sinhalese villager who has been with KCR since its inception and holds the position of controller, for which he is paid by the government; he "disputes that a government-owned radio station is incapable of doing community broadcasting" (Seneviratne, 2007, p. 1). Yet other staff members at KCR are on record as questioning the usefulness of the station to members of their community, such as Tamil tea plantation workers who are considered to be lower caste by Sri Lanka's Sinhalese majority and are largely illiterate labourers. Kosala Keerthiratne, e-tuktuk research coordinator , writes that the Tamil population is disadvantaged by the lack of significant Tamil language interpreters and programming and the lack of educational opportunities for poor Tamils, and she states that the "People in the communities don't feel that these facilities are provided for them too" (Keerthiratne, 2007, p. 1). Keerthiratne goes on to say that Tamil mothers do not encourage their children to get educated or to learn about computers because they have found that their offspring feel unwelcome at the station and the access centres, and, worse, they are not offered better jobs 
because of their minority status even when they are educated and computer literate. In another article that touches on the lack of participation of Tamil tea workers in the KCR and KCRIP project, Keerthiratne writes: "It was like we had forgotten our own neighbours" (2006a, p. 1).

Similarly, Keerthiratne disputes the success of the KCR radio project among young listeners:

Most young people who I talked with seemed to listen to radio but did not seem to listen to Kothmale Community Radio. They did not say it directly. When I asked about the kind of programs that they listen to in Kothmale Community Radio they did not seem to remember any. Most interestingly out of 4 older persons three of them listened to Kothmale radio and did have favourite programs too. (2006b, p. 1)

Former Kothmale staff and volunteers, who have had to leave the station and move on to find paid work to support their families (Op de Coul, 2003), also question the usefulness of the project, hinting that there were many promises made but no effective policies implemented to transform the project into a self-sustaining, community-run station ${ }^{\text {ix }}$. Listened to mostly by a hard core audience of approximately 50 senior citizens (Op de Coul, 2003), most of whom are teachers, monks or priests, KCR, far from being a community radio station, is still owned and operated by the Sri Lanka Broadcasting Corporation, as researchers and former workers make clear (Gunawardene, 2003; Op de Coul, 2003; Venniyoor, 2006). Any station profits are turned over to SLBC rather than used to better equip KCR and KCRIP, hire and train more staff, strengthen its capabilities, better its programming options, expand its reach, or ensure its continued existence. As well, SLBC limits the hours of operation and salary levels of relief staff (Op de Coul, 2003). KCRIP, the Internet project, appears to be used mostly by the young, and while it does successfully promote peer-to-peer training (Pringle, 2001), this success may be mitigated by ethnic tensions between Muslims, Tamils, and the Sinhalese majority.

Significant barriers to community access still exist at Kothmale after more than two decades of operation. The English language barrier, which is rarely addressed by articles extolling the merits of the Kothmale project, is more evident now that the Internet is available for community members to browse. Lack of English-language proficiency necessitates the use of local elites to interpret and put information into local contexts (Dagron, 2001; Pringle, 2001). While some writers say that this service contributes to community cohesiveness, it also means that local elites effectively control access to all information that is not presented in local languages, thus cementing their status as community leaders and further widening the gap to community access by poor labourers who are not of Sinhalese ethnicity. What is rarely noted is that no permanent mechanism exists for community members to publish their information on the Internet in English in order to reach a wider audience (Pringle, 2001).

Credibility is another issue which creates barriers. Much of what is found on the Internet lacks both credibility and scientific rigor, particularly regarding practices needed by farmers for animal 
husbandry, crop information, market rates, etc. The use of volunteer specialists at Kothmale is asserted to be a credibility check (Pringle, 2001, p. 45). However, what if there is no local expert available on the subject being researched, or ethnic tensions do not facilitate a specialist/searcher scenario? Pringle (2001) admits that research supports the finding that, particularly among new users of ICT technology, if irrelevant or incorrect information is obtained by community searchers they will quickly abandon further use of the new technology.

The definition of the concept of participation itself is another barrier to full community access to ICTs. As Pringle (2001) observes, community participation may denote shifting power structures to some people, and this can be empowering or frightening to community members or even threatening to authorities or political leaders. Full participation may never be possible, no matter how strenuously a project is promoted, because ethnic tensions may render certain information unacceptable, regardless of how rigorously it is researched or how well it is presented, and certain segments of a population may feel uncomfortable using it (Pringle \& David, 2002). Furthermore, Pringle (2001) writes that the Food and Agriculture Organization of the United Nations (FAO) disputes the relevance of Western notions of community participation as a construct that has little meaning to non-Western cultures.

Funding for equipment upgrades and repair is proving to be an even bigger barrier to community access than distance or travel time. ${ }^{\mathrm{x}}$ Motivated Internet users willingly travel several hours to reach access centres, but irregular and infrequent funding has meant that KCR needs to charge for Internet access, which limits the ability of many poor families to participate (Op de Coul, 2003). Aging computers, the reassignment of some computers for local urban council uses, and the lack of free or affordable Internet connectivity to other access point computers, have all plagued the Kothmale project since UNESCO discontinued its funding in 2000 (Op de Coul, 2003).

It would appear that KCR and the concept of radio-browsing is more cost-effective and culturally acceptable for older, female listeners than KCRIP because they can enjoy these programs from home. However, the number of young listeners of KCR has dropped off, as previously noted. Young people, particularly young males, tend to be the ones who participate most in the KCRIP Internet project and the training programs offered by the community access centres, but the loss or breakdown of most of their computers stymies their efforts. ${ }^{\mathrm{xi}}$ All of the access barriers noted above leave rural groups of young people with few options but to use the services of the e-tuktuk when (and if) it comes to their village or to move to urban centres to seek ICT training opportunities.

Finally, some activists have noted that four successive governments in Sri Lanka have given broadcast licences to openly political groups and commercial organizations and one licence to the Tamil Tigers to operate their Liberation Tigers of Tamil Eelam (LTTE) channel legally, yet no broadcast licences have been awarded to help legitimize community radio stations in Sri Lanka. It is alleged that this is because of the potential for community radio to freely express political biases, but what of the clearly political commercial radio stations and the broadcast channel of the LTTE (Gunawardene, 2003)? Are commercial stations putting pressure on governments to prevent community radio from becoming commercially viable entities because they fear 
competition or the loss of advertising dollars? These issues are currently not being addressed in Sri Lanka due to ethnic tensions and continued civil war.

\section{Discussion}

While a 2002 Institute of Development Studies (IDS) conference in Kathmandu stated that "sustainability was more a matter of organisation and human resources than finance" (IDS, 2002, p. 3), as regards ICTs, this is clearly wishful thinking. Without ongoing funding or the infrastructure to commercialize community radio to the extent that it can become self-sustaining, community radio cannot continue to operate effectively. Money to maintain Internet connectivity, repair equipment, train volunteers, pay staff, and upgrade to new and better technology has to come from somewhere: benign government intervention, ongoing support from a series of funding agencies, private donors, commercial activities of the station itself, or small mandatory contributions of the listening audience. ${ }^{\text {xii }}$ No station can run on good will and good intentions alone as the Kothmale project has discovered. The Kothmale project lacks the "political power" and "influence" to "leverage the support they need" for self-sufficiency and independent financing (Pringle \& David, 2002, p. 12).

As Pringle and David (2002) have indicated, many studies and surveys, focus groups, and papers have been commissioned to look at the impact of the Kothmale model, and the overall consensus is that not much has changed for the Kothmale community. The main positive impact is that the community members are aware of the power of the Internet and ICTs in general as powerful technological aids (Pringle \& David, 2002). However, it is also clear that introducing technology to a community who embraces it enthusiastically and has used it extensively for over two decades and then substantially depriving them of its ongoing enjoyment in a reliable manner is cruel and can only foment greater unrest and civil disorder as people now know and understand what they are being deprived of.

Bhatnagar et al. have indicated that the involvement of central agencies in the project, such as Sri Lanka Telecom and Colombo University, means that local decision-making and administration is next to impossible (2003, p. 6). Passwords to access and upgrade the Kothmale web site (see http://www.kirana.lk) are retained by staff at Colombo, thus preventing KCR/KCRIP staff from updating the site in a timely manner and rendering its information outdated fairly quickly. To circumvent this situation, KCR staff resorted to creating a parallel web site of their own (see www.kothmale.net). This duplication of effort saps resources and is counter-productive, especially given the difficulties that the project faces in terms of funding, staffing, equipment use, and maintenance, to name a few.

In its publications, UNESCO often notes the importance of free access for the rural poor to the Internet, yet it pulled the bulk of the funding that made this possible without making certain that other reliable mechanisms to sustain the Kothmale project were in place (UNESCO, 2001). Thus, while the channels of communication (Simonson, 2005, p. 264) to enrich the local population and their educational efforts may be appropriate, the funding model for the project is not. As noted, it is pointless for the KCR/KCRIP staff to initiate funding projects if the profits are siphoned off to 
benefit SLBC rather than the project. Prior to initiating the Kothmale project, funders should have negotiated a different arrangement with SLBC. Two decades into the project is too late to begin the process of changing the entrenched attitudes of SLBC administrators about diverting community profits for their own purposes.

Finally, as Wilson points out, providers want to make a profit from their model of e-learning because it is still largely viewed as "an entrepreneurial enterprise" (2005, p. 14), and the Kothmale administrators are no different. SLBC, Kothmale organizers, funders, as well as Sri Lankan government authorities are hopeful that their model can be exported for use by others in a way that will be beneficial and profitable. Even e-tuktuk builders are hopeful that they can create an industry that may grow across Asia and Africa, not to promote and encourage learning as much as to create a profitable growth industry in e-tuktuk outfitting and sales with the resulting jobs and incomes for individual e-tuktuk operators. They also believe that the industry will grow as educational opportunities are encouraged and promoted. This commoditization and commercializing (Wilson, 2005, p. 14) of learning for other purposes is a direct outgrowth of ICT initiatives in distance education.

\section{Conclusion}

As Dagron notes, "Development priorities are to be analysed - hopefully by the beneficiaries before deciding which technology is appropriate, where and how. Communities should adapt technology to their needs and to their culture, not the opposite" (2003, p. 3). In the Kothmale situation, this did not happen. The KCR project was foisted on the communities it serves by a government that was focused on development imperatives and eager to mitigate the problems created by stripping thousands of people of their land and forcibly moving them. ${ }^{\text {xiii }}$ The assumption was made that radio-browsing or Internet technology would be useful for all communities served by the Kothmale project, an idea which the young, at least, appear to have internalized in Sri Lanka (Hughes, 2003). Yet, despite an inauspicious beginning, the Kothmale model has had some notable successes, such as the locally created environmental NGO Green Lanka, which resulted from the Internet training of young Kothmale community members (Hughes, 2003).

The Kothmale project as a whole, while struggling with repeated funding issues, government control, outdated and broken equipment, and ongoing civil unrest and ethnic violence, has managed to successfully train and create a generation of rural Internet users in Sri Lanka. Unfortunately, no one is quite certain how many people, in real numbers, have actually benefitted from this project. KCR and KCRIP have enabled some community members to initiate both continued learning and development projects of their own, and the project has succeeded in educating several generations of community members about the possibilities inherent in ICT technologies. Unfortunately, these gains are offset by a succession of repressive Sri Lankan governments that are intent on limiting ICT-empowered political activism and by the shortsighted decisions of funders. 
The Kothmale project, far from being a model that should be emulated by other nations is, in fact, a cautionary tale about what can go wrong when an ICT project is not strongly promoted as a community-based enterprise. It is both self-serving and misleading of UNESCO and others to promote the Kothmale project as a successful example of community radio when its continued existence is in the hands of a succession of political administrations and international funding agencies with their own economic agendas. The biggest lesson that the Kothmale model can teach us is that control of community radio must be in the hands of the community exclusively if it is to succeed in an ongoing, educational, and culturally-sensitive manner. 


\section{References}

Basu, I. (2008). Sri Lanka-Ingenuity extends mobile communication in remote region. Retrieved from http://www.govtech.com/gt/print article.php?id=261123

Bhatnagar, S., Dewan, A., Torres, M.M., \& Kanungo, P. (2003). Sri Lanka's Kothmale Community Internet Radio Project. In Empowerment case studies: Sri Lanka's Kothmale Community Internet Radio Project. New York: World Bank.

Dagron, A. G. (2001). Kothmale Community Radio Interorg Project (KCRIP). In A.G. Dagron, (Ed.) Making waves: Stories of participatory communication for social change, (pp. 127131). New York: Rockefeller Foundation.

Dagron, A.G. (2003). Take five: A handful of essentials for ICTs in development. In B. Girard (Ed.) The one to watch-radio, new ICT's and interactivity (pp. 21-38). Geneva: FAO.

Etuktuk.net. (2007, July 15). The e-tuktuk project: Partners. Retrieved February, 2008, from http://www.etuktuk.net/partners/

Food and Agriculture Organization (FAO). (2003). Experience 5: Internet radio-Sri Lanka. In Communication and Natural Resources Management (pp. 49-60). Rome: FAO.

Gunawardene, N. (2007, June 4). Lions and community radio: Part of Sri Lanka's mythical lore. Message posted to http://movingimages.wordpress.com/2007/06/04/lions-andcommunity-radio-part-of-sri-lankas-mythical-lore.html

Gunawardene, N. (2003). Radio suffers as Colombo bosses call the shots. Retrieved February, 2008, from http://www.panos.org.uk/newsfeatures/featuredetails.asp?id=1160

Hughes, S. (2003). Community multimedia centres: Creating digital opportunities for all. In B. Girard (Ed.), The one to watch-radio, new ICT's and interactivity (pp. 76-89). Geneva: FAO. http://comunica.org/1-2-watch/pdf/chapter6.pdf

Institute of Development Studies. (2002). Community radio in South Asia: Recommendations and report. In Community radio in South Asia: Exploring the way forward (pp. 1-37). Kathmandu: IDS.

Jayaweera, W. (1998). Internet radio in Sri Lanka. Retrieved February, 2008, from http://www.unesco.org/webworld/highlights/internet_radio_130599.html

Jayaweera, W. (2001). Kothmale Community Radio Internet Report Project: Expanding the knowledge base. Retrieved February 27, 2008, from http://go.worldbank.org/2BP49DV4B0 
Keerthiratne, K. (2006a). A day with the e-tuktuk. Retrieved February, 2008, from http://www.etuktuk.net/a-day-with-the-etuktuk/

Keerthiratne, K. (2006b). A visit to the Kurunduwatta Village. Retrieved February, 2008, from http://www.etuktuk.net/a-visit-to-the-kurunduwatta-village/

Keerthiratne, K. (2007). The e-tuktuk Project. Retrieved February, 2008, from http://www.etuktuk.net/technology/

Kothmale FM community radio. (2001, January). Including the excluded: The Kothmale Experience, 2.

McMichael, P. (2004). Development and social change: A global perspective (3rd ed). Thousand Oaks, CA: Pine Forge Press.

Op de Coul, M. (2003, November 10). Kothmale Community Radio-Sri Lanka. Retrieved February, 2008, from http://www.digitalopportunity.org/article/view/72470

Pringle, I., \& David, M.J.R. (2002). Rural community ICT applications: The Kothmale model. The Electronic Journal of Information Systems in Developing Countries, 8(4), 1-14.

Pringle, I. (2001). Seminar on integrating new and traditional Information and Communication Technologies for community development: Final report. Paris: United Nations Educational, Scientific, and Cultural Organization.

Reddi, U.V., \& Sinha, V. (2007). Sri Lanka: ICT use in education. Retrieved February, 2008, from www.unescobkk.org/fileadmin/user upload/ict/Metasurvey/SRILANKA.pdf

Seneviratne, K. (2000). Media-Sri-Lanka: Rural folks log-on via community radio. Retrieved March, 2008, from http://hrea.org/lists/huridocs-tech/markup/msg00420.html

Seneviratne, K. (2007). Sri Lanka: Building ethnic harmony with community radio. Retrieved March, 2008, from http://www.weeklyholiday.net/2007/220607/inter.html

Simonson, M. (2005). Trends in distance education technologies from an international vantage point. In Y.L. Visser, L. Visser, M. Simonson, \& R. Amirault (Eds.), Trends and issues in distance education: International perspectives (pp. 261-285). Greenwich, CT: IAP Press.

Venniyoor, S. (2006). Sri Lanka's e-tuktuks boldly go where no others have gone before. Retrieved February, 2008, from http://www.infochangeindia.org/features371.jsp

Wilson, B.G. (2005). A survey of progressive and conservative trends in education. In Y.L. Visser, L. Visser, M. Simonson, \& R. Amirault (Eds.) Trends and issues in distance education: International perspectives (pp. 3-21).Greenwich, CT: IAP Press. 


\section{Appendix}

The following points are a direct quote from Pringle and David's (2002, p. 4) study of the Kothmale model.

1. The internet and other new communication technologies should not be presented as a technological gimmick or marvel. They should be presented as something that is useful in day-today life.

2. The first precondition for success is active community participation. For this, the computers and other facilities should be placed and operated in a user friendly manner.

3. Simple step-by-step instructions should be prepared on how to use the Internet and there should be someone at the radio stations and access points to explain the Internet and how it is used.

4. As many do not have telephones the importance of postcards should be emphasized within the radio program.

5. Internet content should be put across the radio program with reference to the local context.

6. As a considerable degree of preparation is needed, a single presenter should not do more than one radio program per week.

7. Women should be encouraged to participate.

8. The local database should be updated regularly taking into account information needs that would emerge within the process.

9. The staff should not be over cautious about breakdowns in computers. The users should be given a free hand. 
i The author uses the word repressive explicitly to showcase the inhibitory nature of successive Sri Lankan governments regarding the freedom of expression available to those accessing the Kothmale Interorg project resources, and the seemingly tacit approval of international funding agencies of these restrictions on free use of a community initiative ostensibly meant to be controlled by the community's inhabitants, not their government. In the case of the Kothmale Interorg project, the Sri Lankan government stringently enforces stipulations on which topics and community groups are too 'political' for inclusion in the initiative. While ostensibly ensuring that radicals do not gain control of the initiative through enforcing strict guidelines for community use of the Kothmale initiative, in actual fact government restrictions have had the effect of denying certain minority groups access to this valuable community resource, even for the most benign, apolitical, educational reasons.

${ }^{\text {ii }}$ In the past, with better funding, the Kothmale project was able to broadcast for 15 hours during the week and up to 20 hours on weekends (UNESCO, 2001).

iii For a list of key points from the Kothmale project's operational guidelines please see Appendix 1.

iv The University of Colombo conducts on-going research to track users' web usage, which they ostensibly plan to publish and offer as a template for other community radio projects (Jayaweera, 1998).

${ }^{v}$ The most recent of these volunteers, Ben Grubb, a former tourist, volunteers his expertise, his time and his money to the project. Mr. Grubb has often contributed his personal funds to help keep KCRIP afloat: particularly in regards to the e-tuktuk part of the project of which he is the coordinator. This situation may soon end, as one tourist of limited means cannot continue to fund repairs of the project on his own (Venniyoor, 2006).

${ }^{v i}$ Funders of the e-tuktuk project include the following: UNESCO, Pan Asia Networking ICT R\&D Grant, Merrill J. Fernando Charitable Foundation, Suntel, Information Communication Technology Agency of Sri Lanka, Sri Lanka Broadcasting Corporation, and Finding a Voice (Etuktuk.net, 2007).

vii The community is attempting to raise money to buy a new, smaller transmitter unit which they can install inside the e-tuktuk, because the e-tuktuk cannot operate during monsoons with a giant transmitter on its roof (Venniyoor, 2006). 
viii Local politicians requested that political opinions not be allowed to be expressed by any political entity on KCR, a fact which some writers use to show that the station is not "controlled by the government" (Pringle, 2001, p. 37). While Sri Lankan media does have a credibility problem as suggested by Pringle, merely refraining from allowing political views to be expressed does not necessarily indicate a lack of government control or promote "good media ethics" and credible journalism (Pringle, 2001, p. 37).

${ }^{\text {ix }}$ Community radio is usually funded at low levels by external funders and is subject to frequent funding fluctuations and stoppages, which means that many workers are either poorly paid or work as volunteers. Eventually these people, often male, although enthusiastic and well-trained, need to move on, albeit reluctantly, because they marry and need to find work which can sustain their families. This is a sore point for many former employees at Kothmale, who maintain that they should have been allowed to turn the station into something larger, better, and selfsustaining. Ultimately, of course, hiring these workers permanently would negate its communal/volunteer nature and turn it into a more commercial entity. This is the paradox facing all communal radio networks.

'Another problem is the Kothmale model's rules of access (See Appendix 1). By allowing users a 'free hand' (Pringle \& David, 2002, p. 4) in using the computers, frequent crashes and breakdowns in equipment limits the enjoyment of the equipment by all potential users.

${ }^{x i}$ The access centres offered training in computer use, Internet and e-mail use, using the Windows suite of products to create documents and spreadsheets and in creating publications, such as news magazines and brochures (Op de Coul, 2003).

xii User costs would change the Kothmale model which has prided itself on being free for users, in particular the rural poor who are its biggest users (Pringle \& David, 2002). Mandating user fees would make the project sustainable in theory, but in practice even more people would opt out of using it because they could not afford it.

xiii McMichael makes the point that integrating poor people into "monetary relations" by selectively relocating them and introducing technology to economically educate and stimulate them discriminates against the traditional knowledge and culture that these people already have (2004, p. 69). 